\title{
Prosthetic rehabilitation after complicated surgical procedures in the anterior region
}

\author{
Senay Cetintas*, Emre Tokar, Elifnur Guzelce and Ozgul Karacaer \\ Department of Prosthodontics, Faculty of Dentistry, Gazi University, Ankara, Turkey
}

\begin{abstract}
Aim: For the success of restoration in cases of prosthetic rehabilitation after complicated surgical procedure in the maxillary anterior region, gums, periodontium, adjacent and antagonist teeth should be included in the planning. In cases requiring multidisciplinary approach, clinicians make consensus by intervening and brings aesthetic success. In this paper, prosthetic examination was performed before the extracting; the prosthetic rehabilitation of the implant superstructure with CAD/ CAM technique after complicated surgical procedures is explained.

Case report: A 56-year-old male patient was admitted to our clinic with pain in the maxillary left central and lateral teeth. The cystic tissue found in the apex of the teeth was resected following the extraction of the teeth and waited for the bone formation. After five months, the bone level was not sufficient for implant placement, and 3cc grafts were applied to the area. After six months of follow-up, two implants were implanted, and four months later prosthetic rehabilitation was initiated. Since the implant levels were less than $8 \mathrm{~mm}$ below the gingiva, a long infrastructure design was needed to cover the abutment step. On the non-parallel implants with the long axis of the natural teeth, CAD / CAM designed laser-sintered metal substructures are used with porcelain. Temporary acrylic restorations were applied to the patient for two months for gingival shaping before prosthetic restoration being permanently cemented with zinc phosphate cement.

Conclusion: No complications were observed biologically and mechanically during the 2-year follow-up period. In patients with zenith point of the smile line before tooth extraction, the prosthetic restorations after bone destruction in the anterior region can be aesthetically satisfactory. Surgical and prosthetic rehabilitations with multidisciplinary approach have provided a high level of protection of bone and surrounding tissues.
\end{abstract}

\section{Introduction}

In dentistry, aesthetics is one of the main factors that brings out the quality of today's work and ensures patient satisfaction [1]. After complicated surgical procedures, the aesthetic after the loss of bone and destruction of soft tissue can be camouflaged by applying gingival color porcelain to the cervical part of the restorations. The use of pinkcolored porcelain, especially in anterior implant restorations, makes smile aesthetics acceptable $[2,3]$.

Correct acquisition of soft tissue contours shaped around an implant located in the anterior region is another important issue affecting the success of restoration [4]. Before surgical operation, prosthetic restoration planned, implant positions and gingival visibility are pre-adjusted, and the existing bone and soft tissue are conservatively protected [5]. The healthy gingiva around the implants ensures that the implants are not infected by the oral cavity. The healthy relationship between the implant-hard tissue and the gingiva-restoration ensures that the implants are long-lasting in the mouth [6].

Today, the use of laser sintered metal infrastructure is highly popular. The CAD/CAM system is more successful and easier than the conservative metal casting technique. With this technique, infrastructures can be produced compatible with periodontal tissues and implant abutments [7]. It is a great advantage that the sintered restorations produced by the CAD/CAM system have lower marginal seals and the cement retention is higher [8,9]. If the formation of papilla between the implant supported restoration and the adjacent permanent tooth fails, the black triangular syndrome causes the accumulation of food residues in the existing space and the deterioration of oral hygiene and aesthetic appearance. The use of temporary acrylic restorations for gingival shaping after implant placement enables the formation of papilla suitable for restoration [3].

In this case, implant supported prosthetic rehabilitation produced by CAD/CAM technique, applied after the extraction of the maxillary lateral and central teeth was explained.

\section{Case report}

A 56-year-old male patient was admitted to Gazi University Faculty of Dentistry with the complaint of pain and mobility in his maxillary left central and lateral teeth. As a result of the detailed anamnesis obtained from the patient, it was found that the patient did not have any systemic discomfort, and that there was no drug allergy except for dust allergy. Two years ago, the maxillary left central tooth was treated with root canal treatment but since the filling was not carried out to the root apex, clinical and radiological examination revealed a cystic tissue extending from the apex of the central and lateral teeth to the apex of the maxillary left molar (Figure 1). Since the cystic tissue was not associated with other teeth apex, only the central and lateral teeth were appropriate for extraction. Before the teeth extraction, the smile line of

*Correspondence to: Senay Cetintas, Department of Prosthodontics, Faculty of Dentistry, Gazi University, Ankara, Turkey, Tel: +90-312-203-4193, E-mail: senaycetintas@windowslive.com

Key words: aesthetic, multidisciplinary approach, anterior region, bone loss

Received: October 11, 2018; Accepted: November 12, 2018; Published: November 15, 2018 
the patient was determined as the zenith point of the teeth. Following the extraction of the teeth, cystic tissue was resected in the same session, and bone formation was expected for five months. It was concluded that the level of bone formed after the tomography was not sufficient for implant placement (Figure 2), then the deficient bone region was covered with membrane by using $3 \mathrm{cc}$ alloplastic xenograft (containing anorganic bovine granules $0.84-2 \mathrm{~mm}$ in size, San Diego, CA, USA). After waiting for six months for bone formation, two implants were placed (Figure 3) and four months later prosthetic rehabilitation phase was started. Due to the fact that the neck of the implants placed according to the current bone level was $8 \mathrm{~mm}$ under the gingiva, a long infrastructure design was needed to cover the abutment step. The CAD/CAM laser-sintered metal infrastructure has been produced on implants which are not parallel to the long axis of natural teeth (Figures 4 and 5). The porcelain was added onto the infrastructure design. Because the smile line was at the level of the cervical region of the teeth, the gingival image was imitated with the pink porcelain in the cervical region of the two produced teeth (Figure 6). The anterior left central tooth was made over-contoured in the cervical area to be similar to the right natural central tooth of the patient (Figure 7).
Since the restoration was in the anterior region and the patient had a class 2 occlusion, the restoration was completed by obtaining a tight contact with the left canine and the right central without being brought in contact with the anterior lower teeth (Figure 8). Our patient was satisfied that the restoration was in harmony with the smile esthetic cause the zenith point of the restoration is on the smile line (Figure 9). First, the restoration was cemented with eugenol free temporary cement. At the end of 4 months, the restoration was permanently fixed with zinc phosphate cement due to the lack of any complaints and no difficulty in adapting the gingiva to the restoration limits (Figure 10).

\section{Discussion}

The problems encountered in the anterior teeth, which play an important role in the aesthetic image, adversely affect the psychological structure of the patient [10]. After resection of cystic tissues that causes bone destruction and requires surgical operation, the use of graft and membrane materials is required for qualified bone formation for the implant placement [11]. Al Ghamdi et al. [12], reported that materials used in the presence of periodontal tissue destruction are autogenous or alloplastic grafts. Since bone formation was not sufficient for the

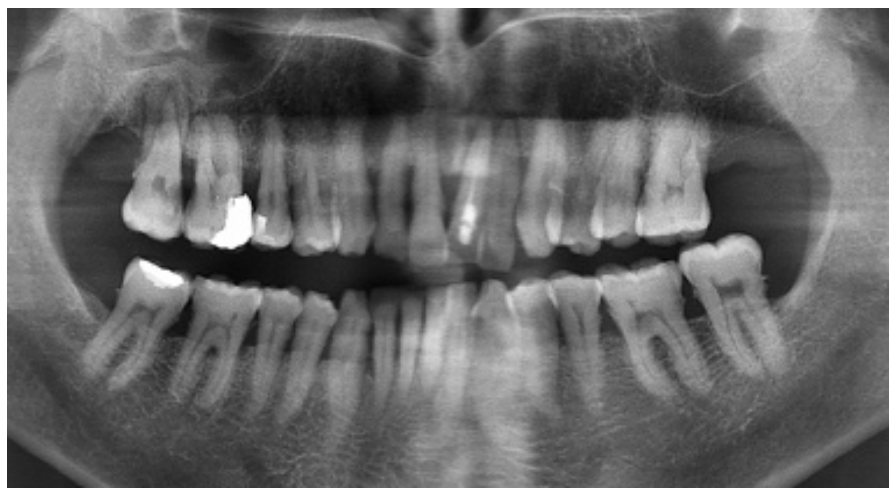

Figure 1. Panoramic view

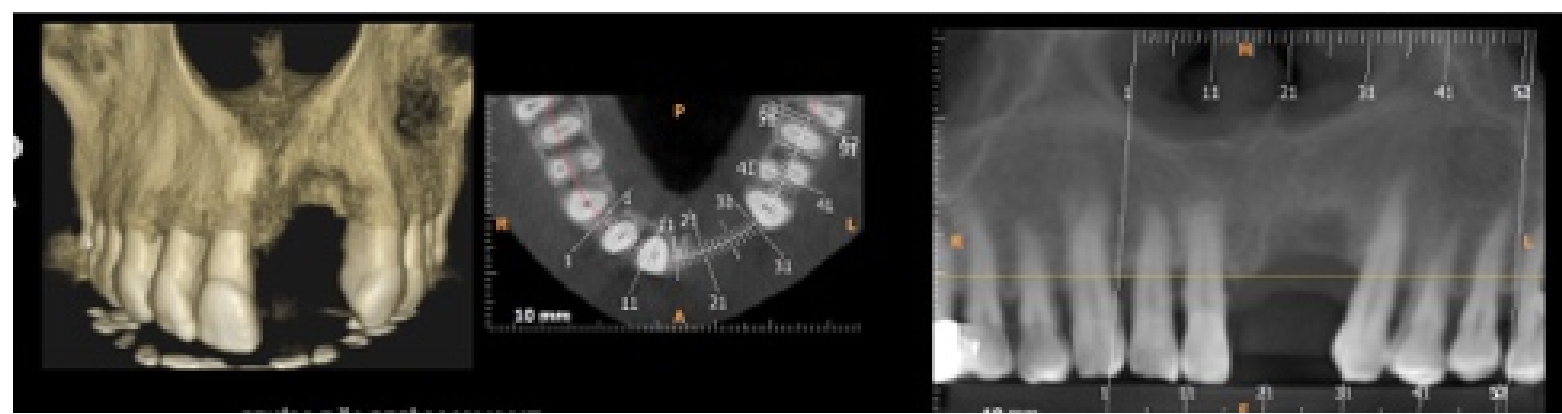

Figure 2. 5th month 3D CBCT image after cyst resection

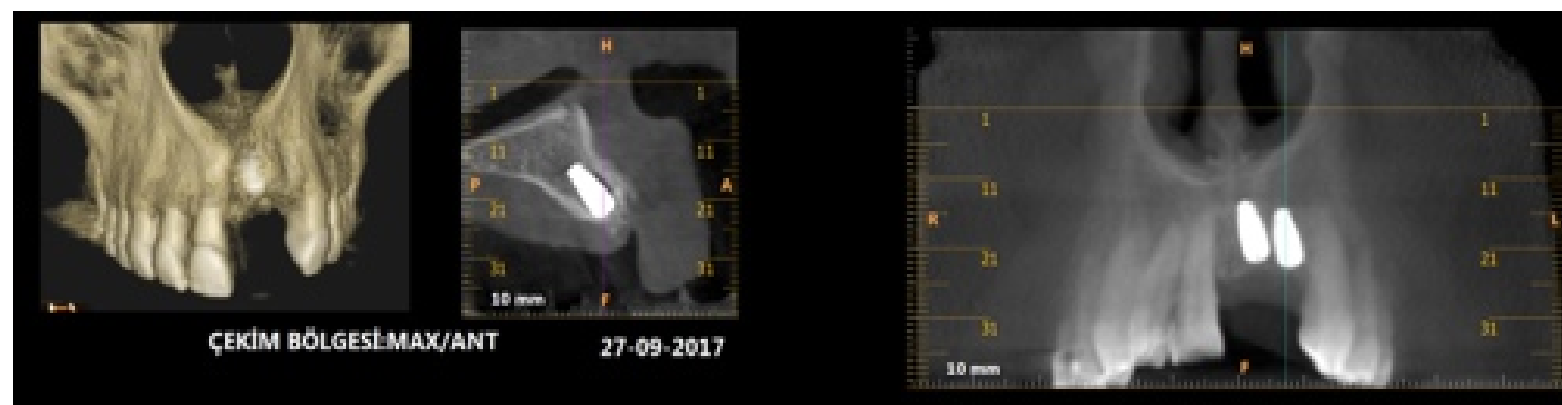

Figure 3. 4th month 3D CBCT image after implant placement 


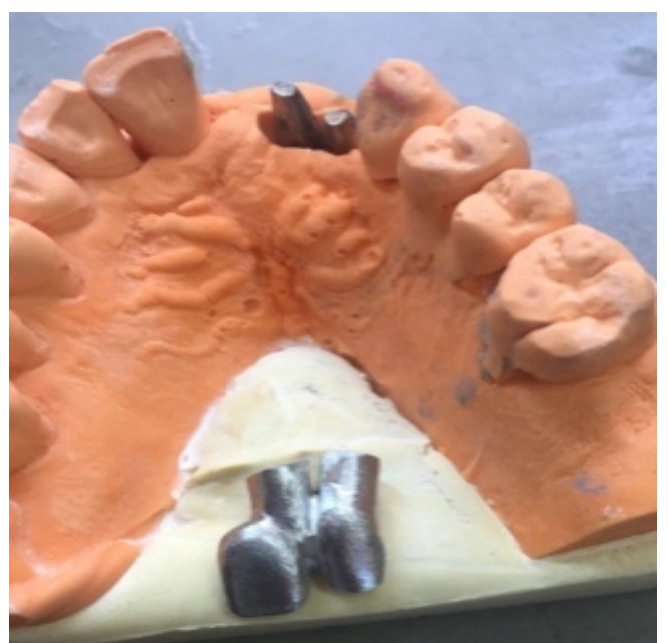

Figure 4. Levels of abutments and $\mathrm{CAD}$ / CAM design laser-sintered metal substructure

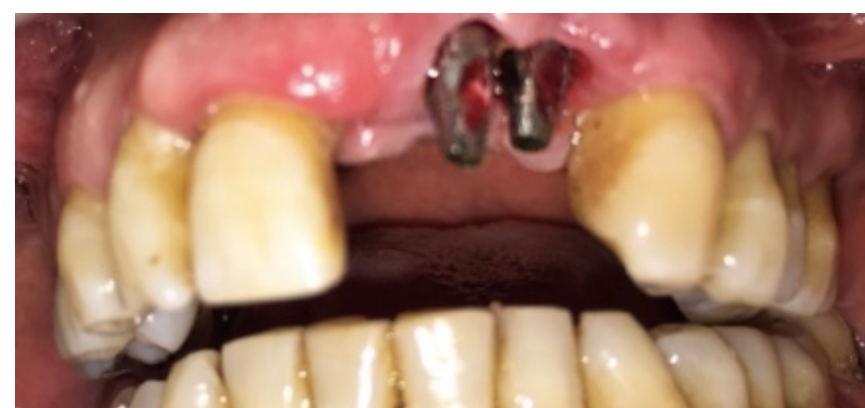

Figure 5. Oral view of the abutments

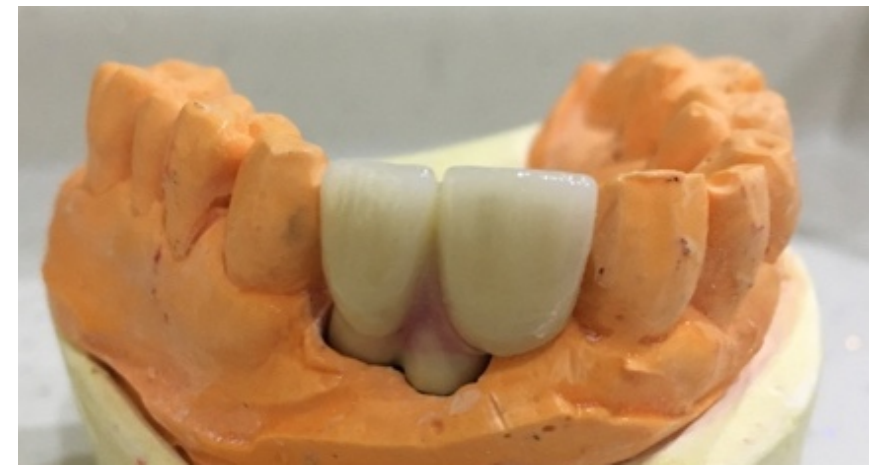

Figure 6. Use of pink porcelain

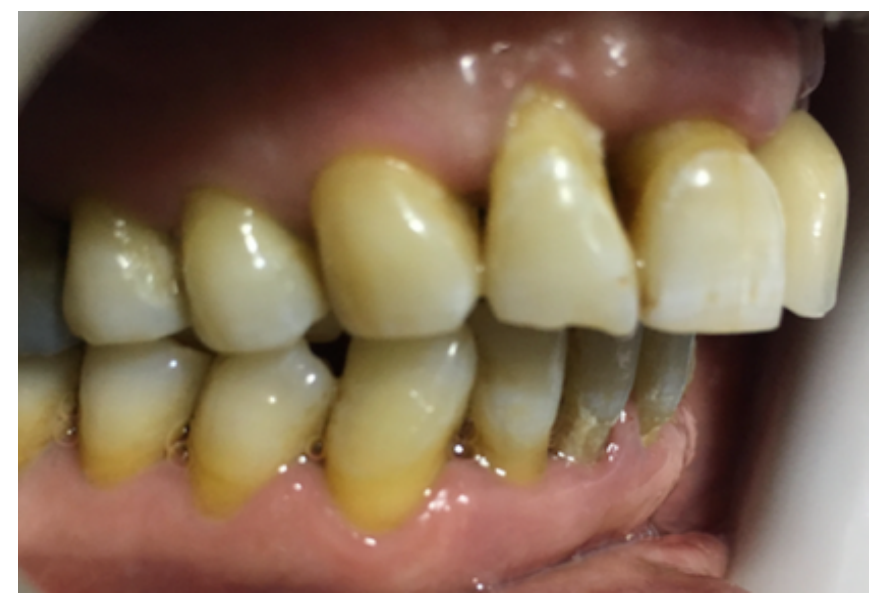

Figure 7. Restoration with over-contour imitation of the right central tooth 


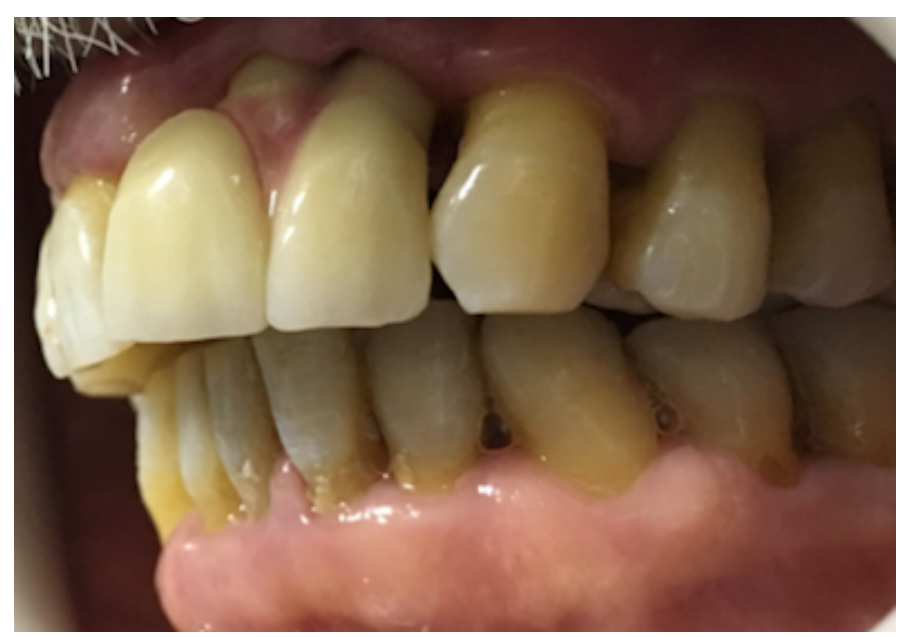

Figure 8. Tight contact with canine tooth

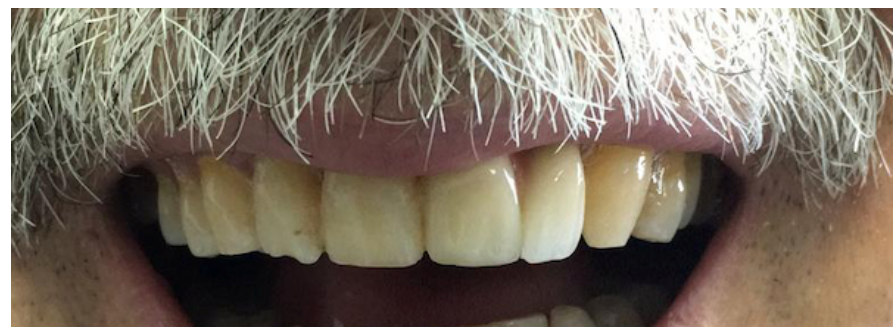

Figure 9. The zenith point of the restoration on the smile line

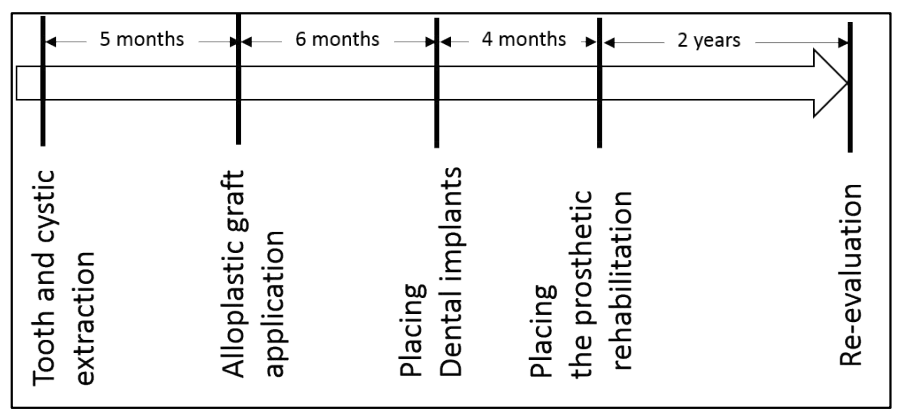

Figure 10. Time schedule of the operations

implant placement in our case after cyst resection, implants were placed using $3 \mathrm{cc}$ alloplastic graft. The region was coated with degradable polytetrafluoroethylene (e-PTFE) membrane and waiting for the bone formation for six months. Fiorellini et al. [13], determined the waiting period as eight months in cases where they placed implants with using bone grafts and polytetrafluoroethylene (e-PTFE) membranes, resulting the healthy osseointegration in all cases. In contrast, there are also studies reporting that graft and membrane applied implant treatments need six months for the formation of healthy osseointegration between implants and bone $[14,15]$. Hur et al. [16] used grafts and membranes with the implant placement in their study and observed the amount of resorption occurring in the graft they use as $20 \%$ in six months.

Implant application in the maxillary anterior region shows more aesthetically and more successful results compared to other treatment options such as fixed prosthetic bridges including healthy teeth preparations, removable prosthesis treatment to recover just two lost teeth in the arch. Making no operation on adjacent teeth is one of the biggest advantages of implant treatment [17]. Priest [18] in the study of 10 years of clinical work with implant treatment has reported that fewer caries, less orthodontic movement risk, less sensitivity, and less plaque retention in adjacent teeth.

In the early period of modern implantology, the main target is tissue health and implant life; in recent years, aesthetics has also gained a significant place among the success criteria of treatment [19]. In the studies, it is stated that the reflection of dark gray colors of metal abutments from gingiva presents an aesthetic disadvantage [20,21]. Since the implant level was $8 \mathrm{~mm}$ below the gingiva and the gingival biotype was relatively thick in our case, ceramic abutment production was not needed. In cases where special design is needed, laser sintered metal infrastructures produced in CAD/CAM system do not have problems such as failure in marginal fit with implant stage and lack of retention like in conventional casting metal infrastructures [7,22,23]. Kim et al. [24] reported that the laser sintered metal infrastructures produced better marginal fit than cobalt-chromium alloys produced by casting technique. Nelson et al. [25] compared metal casting, milling zirconia, zirconia produced with CAD/CAM system and laser sintering metal infrastructures, and laser sintered metal infrastructures showed the best marginal fit and porcelain connection.

The use of laser sintered metal infrastructures, which are more homogenous and more successful in terms of marginal adaptation, is increasing day by day when special design is needed.

The smile aesthetics may be deteriorated due to bone destruction that occurs after anterior tooth loss. The zenith points of the teeth are the most apical point of the cervical tooth margin in the area where the gingiva is the most curvature. The integrity of zenith points ensures the protection of the smile aesthetics [26]. In our case, because the smile line was at the zenith point prior to the tooth extraction, there was no need for a surgical soft tissue arrangement.

In the interdental papillary region, the use of pink porcelain is recommended to prevent the formation of dark areas [3,27]. The use of pink porcelain in order to imitate the papilla between the central and the lateral incisors provided the preservation of the smile aesthetics of our patient.

With the multidisciplinary approach in our case, the patient stated that he did not have any biological or functional problems and he was satisfied with the aesthetic appearance.

\section{Conclusions}

Large cystic tissues cause bone destruction in the apex of the teeth, which makes the placement of the implants very difficult, especially in the presence of spongy bone in the maxillary anterior region. Surgical and prosthetic rehabilitations with multidisciplinary approach provide a high level of protection of bone and surrounding tissues. The relationship between implant-bone and gingival-restoration was evaluated in the control sessions. No complications were observed biologically and mechanically during the 2-year clinical and radiological follow-up (Figure 9). In patients which have smile line at the zenith points before teeth extraction, prosthetic restorations after bone destruction in anterior region may be aesthetically satisfactory.

\section{Acknowledgement}

This case report was presented in $24^{\text {th }}$ International Dental Congress of Turkish Dental Association, Ankara, Turkey.

\section{References}

1. McLaren EA, Goldstein RE (2018) The Photoshop Smile Design Technique. Compend Contin Educ Dent 39: e17-17e20. [Crossref] 
2. Kalman L, MacIntosh K (2013) The use of pink porcelain to manage a malposed anterior implant: case report. J Can Dent Assoc 79: d117. [Crossref]

3. Alani A, Maglad A, Nohl F (2011) The prosthetic management of gingival aesthetics. $\mathrm{Br}$ Dent J 210: 63-69. [Crossref]

4. Spyropoulou PE, Razzoog M, Sierraalta M (2009) Restoring implants in the esthetic zone after sculpting and capturing the periimplant tissues in rest position: a clinical report. J Prosthet Dent 102: 345-347. [Crossref]

5. Ng DY, Wong AY, Liston PN (2012) Multidisciplinary approach to implants: a review. $N Z$ Dent J 108: 123-128. [Crossref]

6. Ivanovski S, Lee R (2018) Comparison of peri-implant and periodontal marginal soft tissues in health and disease. Periodontol 2000 76: 116-130. [Crossref]

7. Afify A, Haney S, Verrett R, Mansueto M, Cray J, et al. (2018) Marginal discrepancy of noble metal-ceramic fixed dental prosthesis frameworks fabricated by conventional and digital technologies. J Prosthet Dent 119: 307. [Crossref]

8. Gomez-Meda R, Montoya-Salazar V, Dalmau S, Torres-Lagares D (2018) Three steps to maintain predictable interdental papilla and gingiva emergence profiles in immediate implant placement. A 3-year follow-up case report. J Clin Exp Dent 10: 513-519. [Crossref]

9. Muratomi R, Kamada K, Taira Y, Higuchi S, Watanabe I, et al. (2013) Comparative study between laser sintering and casting for retention of resin composite veneers to cobalt-chromium alloy. Dent Mater J 32: 939-945.

10. Korkut B, Yanikoglu F, Tagtekin D (2016) Direct Midline Diastema Closure with Composite Layering Technique: A One-Year Follow-Up. Case Rep Dent 2016: 1-5. [Crossref]

11. Kohal RJ, Mellas P, Hürzeler MB, Trejo PM, Morrison E, et al. (1998) The Effects of Guided Bone Regeneration and Grafting on Implants Placed into Immediate Extraction Sockets. An Experimental Study in Dogs. J Periodontol 69: 927-937. [Crossref]

12. AlGhamdi AS, Shibly O, Ciancio SG (2010) Osseous grafting part II: xenografts and alloplasts for periodontal regeneration--a literature review. J Int Acad Periodontol 12 : 39-44. [Crossref]

13. Fiorellini JP, Kim DM, Nakajima Y, Weber HP (2007) Osseointegration of titanium implants following guided bone regeneration using expanded polytetrafluoroethylene membrane and various bone fillers. Int J Periodontics Restorative Dent 27: 287-294. [Crossref]
14. Misch CM (2017) Horizontal Alveolar Ridge Augmentation in Implant Dentistry. Implant Dent 26: 2-3.

15. Kumar P, Vinitha B, Fathima G (2013) Bone grafts in dentistry. J Pharm Bioallied Sci 5: S125-127. [Crossref]

16. Hur Y, Ogata Y, Kim DW, Pham CM, Yoon TH, et al. (2017) Bone Resorption During Submerged Healing After Guided Bone Regeneration: A Prospective Case Series. Implant Dent 26: 820-825. [Crossref]

17. Misch C. Üst Çene Ön Bölgede Tek Dis Eksikligi ve Tedavisi. Kutay Ö Istanbul: Nobel Tip Kitabevleri; 2009.

18. Priest G (1999) Single-tooth implants and their role in preserving remaining teeth: a 10-year survival study. Int J Oral Maxillofac Implants 14: 181-188. [Crossref]

19. Sennerby L, Odman J, Lekholm U, Thilander B (1993) Tissue reactions towards titanium implants inserted in growing jaws. A histological study in the pig. Clin Oral Implants Res 4: 65-75. [Crossref]

20. Andreiotelli M, Wenz HJ, Kohal RJ (2009) Are ceramic implants a viable alternative to titanium implants? A systematic literature review. Clin Oral Implants Res 20: 32-47. [Crossref]

21. Sailer I, Philipp A, Zembic A, Pjetursson BE, Hämmerle CH, et al. (2009) A systematic review of the performance of ceramic and metal implant abutments supporting fixed implant reconstructions. Clin Oral Implants Res 20: 4-31. [Crossref]

22. Yilmaz B, Alshahrani FA, Kale E, Johnston WM (2018) Effect of feldspathic porcelain layering on the marginal fit of zirconia and titanium complete-arch fixed implantsupported frameworks. J Prosthet Dent 120: 71-78. [Crossref]

23. Xu D, Xiang N, Wei B (2014) The marginal fit of selective laser melting-fabricated metal crowns: an in vitro study. J Prosthet Dent 112: 1437-1440. [Crossref]

24. Kim EH, Lee DH, Kwon SM, Kwon TY (2017) A microcomputed tomography evaluation of the marginal fit of cobalt-chromium alloy copings fabricated by new manufacturing techniques and alloy systems. J Prosthet Dent 117: 393-399. [Crossref]

25. Nelson N, K S J, Sunny K (2017) Marginal Accuracy and Internal Fit of Dental Copings Fabricated by Modern Additive and Subtractive Digital Technologies. Eur J Prosthodont Restor Dent 25: 20-25.

26. Basaran S, Yamanel K. Gülümseme Tasarimi. A Ü Dis Hek Fak Derg. 2015;42(2):123-134

27. Barzilay I, Irene T (2003) Gingival prostheses--a review. J Can Dent Assoc 69: 74-78. [Crossref]

Copyright: (C)2018 Cetintas S. This is an open-access article distributed under the terms of the Creative Commons Attribution License, which permits unrestricted use, distribution, and reproduction in any medium, provided the original author and source are credited. 